\section{Virtual Reality: A Source to Improve Physical and Mental Wellbeing}

\section{Sir,}

Physical and mental health are important factors in our lives. Healthcare professionals strive hard to improve people's health and quality of life. There have been remarkable technological advances in the last few decades, which have positively impacted and improved medical and healthcare delivery. Virtual reality (VR) is a recent development with potential for application in healthcare. It is an interaction of human beings with the computer in a space that is functional and realistic. It provides sensorimotor as well as cognitive activities in a simulated environment. VR has been used in many medical fields, but the current biggest user of this technology is rehabilitation science. ${ }^{1}$ VR based exercise games are not only engaging and motivating, but also provides feedback that informs the user about his/her performance level and he/she may set targets, accordingly. VR-based games have been found effective in treating various physical and mental symptoms caused by different diseases including diabetes, stroke, Parkinson disease, spinal cord injury, traumatic brain injury, multiple sclerosis, cerebral palsy and ageing. ${ }^{2,3}$

There is evidence that exercise gaming improves sensory and motor functions, strength, balance coordination, reaction time and activity levels. ${ }^{2-4}$ It not only improves the physical aspects, but also has psychological benefits. ${ }^{5}$ It enhances learning and cognition, and also helps resolve depression in subjects with chronic illnesses. Majority of its use is for subjects having different physical and psychological disorders, but it can be used for health promotion as well. It can improve the quality of life and help fight ageing in the elderly. In pediatric age group, it may increase learning abilities and problem-solving skills as well as act as a source of healthy physical activity. In healthy adults VR is a reliable tool to develop and maintain fitness levels. It is also beneficial for relieving everyday stresses and depressions. $^{5}$

Virtual reality-based games are being used for the last decade worldwide for fitness and rehabilitative purposes, and have demonstrated positive effects. VR is recently being used in Pakistan mainly by physical therapists to manage balance and coordination issues related to stroke, multiple sclerosis and cerebral palsy. We should use the range of each VR devices with its own unique features for physical and psychological well- being, too. It may eliminate risks of various diseases to develop; and is also a source of healthy lifestyle. As healthcare professionals, we should encourage VR as a tool to improve physical and mental well-being.

\section{CONFLICT OF INTEREST:}

The authors declared no conflict of interest.

\section{AUTHORS' CONTRIBUTION:}

KK: Conception, design, analysis, final approval for version to be published.

NS: Conception, drafting and critical review.

MMAA: Design, drafting of work and critical review.

\section{REFERENCES}

1. Klinger E, Weiss PL, Joseph PA. Virtual reality for learning and rehabilitation. Rethinking physical and rehabilitation medicine: Springer 2010; 203-21.

2. Khushnood K, Sultan N, Mehmood R, Qureshi S, Tariq H, Amjad I. Does wii fit balance training improve balance and reduce fall risk in diabetic patients as compared to balance training exercises? A randomized control trial. Rawal Med J 2019; 44(1):44-8.

3. Fleming TM, Bavin L, Stasiak K, Hermansson-Webb E, Merry SN, Cheek C, et al. Serious games and gamification for mental health: Current status and promising directions. Frontiers Psychiatry 2017; 7:215.

4. Thornton M, Marshall S, McComas J, Finestone $H$, McCormick A, Sveistrup $H$. Benefits of activity and virtual reality based balance exercise programmes for adults with traumatic brain injury: perceptions of participants and their caregivers. Brain Inj 2005; 19(12):989-1000.

5. Zeng N, Pope Z, Lee JE, Gao Z. Virtual reality exercise for anxiety and depression: A preliminary review of current research in an emerging field. J Clin Med 2018; 7(3):42.

Kiran Khushnood ${ }^{1}$, Nasir Sultan ${ }^{2}$ and Malik Muhammad Ali Awan ${ }^{1}$

${ }^{1}$ Department of Physical Therapy, Shifa Tameer-e-Millat University, Islamabad, Pakistan

${ }^{2}$ Department of Rehabilitation, Shifa International Hospital, Islamabad, Pakistan

Correspondence to: Dr. Kiran Khushnood, Department of Physical Therapy, Shifa Tameer-e-Millat University, Islamabad, Pakistan

E-mail: kirankhushnood@yahoo.com

Received: October 18, 2019; Revised: December 11, 2019; Accepted: January 24, 2020

DOI: https://doi.org/10.29271/jcpsp.2020.09.999 